\title{
Pharmacokinetic Interaction Between Simvastatin and Fenofibrate With Staggered and Simultaneous Dosing: Does It Matter?
}

The Journal of Clinical Pharmacology 54(9) 1038-1047

(C) 2014, The American College of Clinical Pharmacology DOI: $10.1002 / j c p h .291$

\section{Anneke Winsemius, MSc', Jean-Claude Ansquer, $\mathbf{M D}^{2}$, Matthias Olbrich, $\mathrm{PhD}^{3}$, Peter van Amsterdam, MSc', Patrick Aubonnet, MD ${ }^{4}$, Katrin Beckmann, MSc $^{3}$, Stefan Driessen, PhD', Hanneke van Assche, MSc', Gabi Piskol, BSc ${ }^{5}$, Dirk Lehnick, $\mathbf{P h D}^{5}$, and Katsuhiro Mihara, $\mathbf{P h D}^{\prime}$}

\begin{abstract}
Simvastatin and fenofibrate are frequently co-prescribed at staggered intervals for the treatment of dyslipidemia. Since a drug-drug interaction has been reported when the two drugs are given simultaneously, it is of clinical interest to know whether the interaction differs between simultaneous and staggered combinations. A study, assessing the impact of both combinations on the interaction, was conducted with 7-day treatment regimens using simvastatin $40 \mathrm{mg}$ and fenofibrate $145 \mathrm{mg}$ : (A) simvastatin only (evening), (B) simvastatin and fenofibrate (both in evening), and (C) simvastatin (evening) and fenofibrate (morning). Eighty-five healthy subjects received the respective treatments in a randomized, 3-way cross-over study. The pharmacokinetics of simvastatin and the active metabolite simvastatin acid were determined. There was a limited reduction in the $A_{U} C_{0-24 h}$ of simvastatin acid of $2 \mathrm{I}$ and $29 \%$ for simultaneous and staggered combination, respectively. The geometric mean $\mathrm{AUC}_{0-24 \mathrm{~h}}$ ratio of simvastatin acid for the two combined dosing regimens $(B / C)$ and $90 \%$ confidence interval were III\% (I02-12I). The interaction apparently had no impact on lipid markers. The findings imply that the observed pharmacokinetic interaction is unlikely clinically relevant, and support the combined use of simvastatin and fenofibrate not only given at staggered interval but also given simultaneously.
\end{abstract}

\section{Keywords}

simvastatin, fenofibrate, coadministration, pharmacokinetic, drug-drug interaction

Simvastatin and fenofibrate are lipid-regulating agents often co-prescribed in the treatment of dyslipidemia. ${ }^{1}$ Simvastatin reduces blood concentrations of low-density lipoprotein cholesterol by inhibition of the 3-hydroxy-3methyl-glutaryl-coenzyme A (HMG-CoA) reductase enzyme. Fenofibrate reduces blood concentrations of triglycerides and increases concentrations of high-density lipoprotein cholesterol through activation of peroxisome proliferator-activated receptor alpha.

Simvastatin is an inactive lactone which is hydrolyzed, mainly in the liver, to form metabolites, including simvastatin acid (SVA), a potent inhibitor of HMGCoA reductase.

Fenofibrate is rapidly hydrolyzed by esterases to the active metabolite fenofibric acid. No unchanged fenofibrate can be detected in the plasma. Simvastatin is metabolized by CYP $3 \mathrm{~A} 4$ enzymes while fenofibrate is not a substrate for or an inhibitor of CYP 3A4. No hepatic microsomal metabolism for fenofibrate is involved.

In a small study using simultaneous administration of fenofibrate and simvastatin, a pharmacokinetic drug interaction between the two drugs has been reported. ${ }^{2}$ Bergman et al showed a mean reduction of $36 \%(90 \%$ confidence interval (CI): $30-42$ ) in the $\mathrm{AUC}_{0-24 \mathrm{~h}}$ (area under the plasma concentration curve) of the active metabolite SVA after multiple simultaneous coadministration of $160 \mathrm{mg}$ fenofibrate and $80 \mathrm{mg}$ simvastatin in healthy subjects.

The authors concluded that the observed interaction after simultaneous combination was not clinically significant as there was no relevant effect on the HMG-

\footnotetext{
'Abbott Healthcare Products B.V., Established Pharmaceuticals, Weesp, The Netherlands

${ }^{2}$ ClinSciences, Dijon, France

${ }^{3}$ Abbott Laboratories GmbH, Established Pharmaceuticals, Hannover, Germany

${ }^{4}$ Abbott Products Operations AG, Established Pharmaceuticals, Allschwil, Switzerland

${ }^{5}$ Nuvisan GmbH, Neu Ulm, Germany
}

Submitted for publication 29 January 20I4; accepted 2I March 2014.

\section{Corresponding Author:}

Anneke Winsemius, MSc, Abbott Healthcare Products B.V., C.J. van Houtenlaan 36, Weesp I38I CP, The Netherlands

Email: anneke.winsemius@abbott.com 
CoA reductase inhibitor activity and no relevant changes in fenofibric acid kinetics were observed.

Importantly, instead of simultaneous combination, in clinical practice the two drugs are often given in a staggered manner (e.g., simvastatin given in the evening and fenofibrate in the morning). As far as a pharmacokinetic interaction is concerned for the combination of simvastatin and fenofibrate, no evidence is available which would support interchangeability of the two combination regimens. Therefore, to bridge to clinical practice, there was interest to investigate whether the drug-drug interaction would be similar between simultaneous and staggered combinations.

Additionally, appropriate assessment of the degree of the pharmacokinetic interaction observed by Bergman et al might be hampered due to the limited sample size $(\mathrm{n}=12)$ of their study and the large data variability (coefficient of variation $(\mathrm{CV})$ for SVA $\mathrm{AUC}_{0-24 \mathrm{~h}}$ being $90-100 \%$ ).

For these reasons we felt that further investigations were necessary to evaluate the pharmacokinetic interaction of the two drugs, whether given simultaneously or in a staggered manner. A large pharmacokinetic interaction study involving 85 healthy subjects was conducted in order to compare the pharmacokinetic profile of simvastatin and SVA after simultaneous and staggered dosing of simvastatin and fenofibrate.

\section{Methods}

The study protocol was approved by the Ethics Committee of the General Medical Council North Rhine and by the National Agency of Medicines in Germany. All subjects gave their written informed consent before participation.

\section{Subjects}

A total of 85 healthy, nonsmoking, male (51) and female (34) subjects participated in the study. Subjects were of White (83) or Asian (2) race. Before they entered the study, their health status was assessed by medical history, physical examination, vital signs, ECG, and routine laboratory tests. Females had to be of nonchildbearing potential or have a negative serum $\beta$-human chorionic gonadotropin ( $\beta$-HCG) test and to use an accepted form of contraception. Pregnancy tests were repeated prior to admission to each study period. All subjects were genotyped for SLCO1B1 single nucleotide polymorphisms $521 \mathrm{~T}>\mathrm{C}$ and $388 \mathrm{~A}>\mathrm{G}$. Their mean (range) age was 39 (21-55) years, mean body weight $72 \mathrm{~kg}$ (51-102 kg), mean height $174 \mathrm{~cm}(154-196 \mathrm{~cm})$, and mean BMI $24 \mathrm{~kg} / \mathrm{m}^{2}\left(19-27 \mathrm{~kg} / \mathrm{m}^{2}\right)$.

\section{Study Design}

The study consisted of three periods in which subjects received in randomized order one of the following treatments from day 1 through day 7: one simvastatin $40 \mathrm{mg}$ tablet taken in the evening at around $8 \mathrm{pm}$ (treatment A), one simvastatin $40 \mathrm{mg}$ tablet and one fenofibrate $145 \mathrm{mg}$ tablet taken together in the evening at around $8 \mathrm{pm}$ (treatment B), or one simvastatin $40 \mathrm{mg}$ tablet taken in the evening at around $8 \mathrm{pm}$ and one fenofibrate $145 \mathrm{mg}$ tablet taken in the morning at approximately $8 \mathrm{am}$ ( 12 hours before the simvastatin dosing) (treatment C). All doses were taken with $200 \mathrm{~mL}$ water. Evening doses were given after a standard dinner and subjects remained in upright position for at least 2 hours prior to sleep. Morning doses were given in the fasted state. Treatment periods were separated by a wash-out of one week. Blood samples $(4 \mathrm{~mL})$ for determination of plasma profiles of the parent compound simvastatin and the SVA metabolite were drawn before and $0.5,1,1.5,2,2.5,3,4,5,6,8,10,12,16$, and 24 hours after dosing on day 1 and day 7 . Assessment of steady-state for fenofibrate was verified on the basis of trough plasma concentrations of fenofibric acid concentrations. Blood samples $(4 \mathrm{~mL})$ were taken prior to the first dose of fenofibrate and on days 6, 7, and 8 (24hours after previous dose). All blood samples were collected into $4 \mathrm{~mL}$ sodium-heparin vacutainers and placed in an icewater bath immediately after sampling. Plasma was separated in a cooled centrifuge within 15 minutes after blood sampling. For simvastatin and simvastatin hydroxyacid analysis the plasma samples were, to stabilize the samples, subsequently acidified with phosphoric acid before storage at $-70^{\circ} \mathrm{C}$ until analysis. Fenofibric acid samples were stored at $-20^{\circ} \mathrm{C}$ without any stabilization pre-treatment. Blood sampling for the determination of low density lipoprotein cholesterol (LDL-C), total cholesterol, triglycerides, and high density lipoprotein cholesterol (HDL-C) concentrations was done in the fasting state on day 1 (before dosing) and day 8 of each period.

The products used in this study were simvastatin (Zocor Forte $^{\circledR} 40 \mathrm{mg}$ MSD GmbH, Haar, Germany) and fenofibrate (Lipidil $145 \mathrm{ONE}^{\mathbb{R}}$, Abbott Arzneimittel GmbH, Hanover, Germany). Use of other drugs (with the exception of contraceptives in women of childbearing potential and of limited amounts of analgesics) was prohibited for 2 weeks and use of grapefruit juice, methylxanthines, or alcohol was prohibited for 2 days prior to administration of study drugs and until end of study.

\section{Safety Assessments}

Safety and tolerability were assessed by physical examination, vital signs, electrocardiogram, routine laboratory tests (hematology, biochemistry, and urinalysis), pregnancy tests, and adverse events reporting.

\section{Determination of Plasma Concentrations}

Plasma sample analysis and validation of the bioanalytical methods were done in accordance with the current EMA guideline on bioanalytical validation. ${ }^{3}$

The concentrations of simvastatin and its metabolite simvastatin acid were measured with a stable isotope 
labeled internal standard high performance liquid chromatography-tandem mass spectrometry (LC-MS/MS) method using an AB SCIEX Triple Quad 5500 (AB SCIEX, Framingham, MA, USA) operating in positive ion turbo spray mode. Chromatography was performed on $1.7 \mu \mathrm{m}$ Kinetex XB-C18 column $\left(50 \times 2.1 \mathrm{~mm}^{2}\right.$ internal diameter) (Phenomenex, Torrance, CA, USA) by use of an isocratic elution with $2.5 \mathrm{mMol} / \mathrm{L}$ ammonium trifluoroacetate in water-methanol (31:69). The ion transitions monitored were mass-to-charge ratio (m/z) 419 to $\mathrm{m} / \mathrm{z} 285$ for simvastatin, $\mathrm{m} / \mathrm{z} 425$ to $\mathrm{m} / \mathrm{z} 285$ for simvastatin-d6 (internal standard), $\mathrm{m} / \mathrm{z} 437$ to $\mathrm{m} / \mathrm{z} 303$ for simvastatin hydroxyacid, and $\mathrm{m} / \mathrm{z} 443$ to $\mathrm{m} / \mathrm{z} 303$ for simvastatin hydroxyacid-d6 (internal standard). The limit of quantification for simvastatin and its hydroxyacid metabolite, processing a $250 \mu \mathrm{L}$ plasma sample, was $0.1 \mathrm{ng} / \mathrm{mL}$. The assay performance characteristics for simvastatin were: coefficient of variation $(\mathrm{CV}) 3.4 \%$ at $0.1 \mathrm{ng} / \mathrm{mL}(\mathrm{n}=91)$, $8.3 \%$ at $0.3 \mathrm{ng} / \mathrm{mL}(\mathrm{n}=179), 6.5 \%$ at $4 \mathrm{ng} / \mathrm{mL}(\mathrm{n}=185)$, and $5.9 \%$ at $40 \mathrm{ng} / \mathrm{mL}(\mathrm{n}=185)$. The accuracy, expressed as bias, was $0.3,-2.2,-0.1$, and $-2.5 \%$, respectively. Fenofibric acid plasma concentrations were measured with an analogue internal standard LC-MS/MS method. The system was an Applied Biosystems API 3000 (AB SCIEX, Framingham, MA, USA) operating in positive ion turbo spray mode. Chromatography was done on a $5 \mu \mathrm{m}$ YMC-Pack ODS-AQ column $\left(50 \times 2.1 \mathrm{~mm}^{2}\right.$ internal diameter) (YMC Europe $\mathrm{GmbH}$, Dinslaken, Germany) by use of an isocratic elution with $0.4 \mathrm{mmol} / \mathrm{L}$ ammonium formiate in water-methanol (30:70). The ion transitions monitored were: $\mathrm{m} / \mathrm{z} 319$ to $\mathrm{m} / \mathrm{z} 233$ for fenofibric acid and $\mathrm{m} / \mathrm{z} 255$ to $\mathrm{m} / \mathrm{z} 209$ for ketoprofen (internal standard). The lower limit of quantification, processing a $100 \mu \mathrm{L}$ plasma sample, was $10 \mathrm{ng} / \mathrm{mL}$. The precision of the method, expressed as $\mathrm{CV}$, was $0.7 \%$ at $10 \mathrm{ng} / \mathrm{mL}(\mathrm{n}=7), 6.8 \%$ at $30 \mathrm{ng} / \mathrm{mL}(\mathrm{n}=19), 5.1 \%$ at $300 \mathrm{ng} / \mathrm{mL}(\mathrm{n}=19)$, and $5.9 \%$ at $4,000 \mathrm{ng} / \mathrm{mL}(\mathrm{n}=19)$. Accuracies were $2.5,5.2,2.8$, and $4.4 \%$, respectively.

\section{Determination of Lipid Markers}

LDL-C serum concentrations were measured with a test kit from Roche Diagnostics based upon an enzymatic colorimetric assay on a Roche/Hitachi/MODULAR P800 analyzer (Hitachi Ltd. Tokyo, Japan). The lower limit of quantification was $6 \mathrm{mg} / \mathrm{dL}(0.16 \mathrm{mmol} / \mathrm{L})$. The precision was $3.5 \%$ at $58 \mathrm{mg} / \mathrm{dL}(\mathrm{n}=19), 2.1 \%$ at $101 \mathrm{mg} / \mathrm{dL}$ $(\mathrm{n}=19)$, and $1.6 \%$ at $210 \mathrm{mg} / \mathrm{dL}(\mathrm{n}=20)$ and the accuracy was $0.2,-0.7$, and $3.4 \%$, respectively.

HDL-C serum concentrations were measured using the HDL-C plus 3rd generation test kit from Roche Diagnostics, based on an homogeneous enzymatic colorimetric assay, and the triglycerides concentrations were assessed using a GPO-PAP test kit from Roche Diagnostics also based on an homogeneous enzymatic colorimetric assay.

\section{Determination of SLCOIBI Single Nucleotide Polymorphisms}

SLCO1B1 single nucleotide polymorphisms $521 \mathrm{~T}>\mathrm{C}$ and $388 \mathrm{~A}>\mathrm{G}$ were determined on a full blood sample (EDTA-tube) by pyrosequencing.

\section{Pharmacokinetics}

The following pharmacokinetic parameters for unchanged simvastatin and SVA were determined in the 24-hour interval after single and/or multiple dose administration: $\mathrm{AUC}_{0-24 \mathrm{~h}}, \mathrm{AUC}, \mathrm{C}_{\max }, \mathrm{T}_{\max }, \mathrm{t}_{1 / 2}, \mathrm{CL} / \mathrm{F}$, $\mathrm{V}_{\mathrm{z}} / \mathrm{F}, \mathrm{C}_{\mathrm{min}}, \mathrm{C}_{\mathrm{avg}}$, and PTF (peak trough fluctuation). CL/F and $\mathrm{V}_{\mathrm{z}} / \mathrm{F}$ were calculated for simvastatin only.

At time points in the lag-time between time zero and the first concentration equal or above lower limit of quantification (LLOQ), concentrations below LLOQ were set to zero. For the calculation of PK parameters concentrations below LLOQ between two concentrations equal or above LLOQ were set to missing. The AUC parameters were calculated according to the lin-up logdown trapezoidal rule. The values of $\mathrm{C}_{\max }$ and $\mathrm{T}_{\max }$ were taken directly from the individual concentration versus time data. The elimination rate constant $\left(\lambda_{\mathrm{z}}\right)$ was estimated by log-linear least squares regression of the terminal part of the plasma concentration versus time curve. The $t_{1 / 2}$ was calculated by the equation $t_{1 / 2}=\ln 2 / \lambda_{z}$.

\section{Pharmacodynamics}

Plasma concentrations of LDL-C, HDL-C, total cholesterol, and triglycerides were determined before and after each treatment regimen. The correlation between SVA $\mathrm{AUC}_{0-24 \mathrm{~h}}$ after multiple dosing and plasma LDL-C concentrations on day 8 (actual and changes from baseline) was explored.

\section{Statistical Analysis}

Statistical analysis was performed in accordance with the current EMA Guideline on the Investigation of Bioequivalence. $^{4}$

Primary PK parameters were $\mathrm{AUC}_{0-24 \mathrm{~h}}$ and $\mathrm{C}_{\max }$ for simvastatin and SVA after multiple dose administration. Each parameter was compared between the three treatment regimens taking into account period and subject. The primary comparison was for SVA $\mathrm{AUC}_{0-24 \mathrm{~h}}$ after multiple dose administration between treatment $\mathrm{B}$ and $\mathrm{C}$. The $\mathrm{B} / \mathrm{C}$ ratios of geometric means and their $90 \%$ CI would permit to indicate bioequivalence (administration of fenofibrate and simvastatin together vs. administration of fenofibrate and simvastatin at 12-hour interval).

The geometric mean $\mathrm{B} / \mathrm{A}$ and $\mathrm{C} / \mathrm{A}$ ratios and their $90 \%$ $\mathrm{CI}$ for SVA $\mathrm{AUC}_{0-24 \mathrm{~h}}$ were used for the analysis of a potential pharmacokinetic interaction.

Similar comparisons were made for $\mathrm{AUC}_{0-24 \mathrm{~h}}$ of the parent compound simvastatin and for $\mathrm{C}_{\max }$ of SVA and simvastatin, both after single and multiple dosing. 
The $90 \%$ CI for the geometric mean ratios were derived from a general linear model analysis of variance with sequence, subjects within sequence, period, and treatment as fixed effects comparing the log transformed values for $\mathrm{AUC}_{0-24 \mathrm{~h}}$ and $\mathrm{C}_{\max }$. The resultant ratio of geometric means expressed as percentage and $90 \%$ CI were obtained after anti-logarithmic transformation of the results of the general linear model.

Only subjects with sufficient data to calculate a complete set of the primary PK parameters for at least one treatment regimen and who had no major protocol deviations affecting the integrity of the PK data were included in the PK analysis.

LDL-C, total cholesterol, triglycerides, HDL-C data were summarized by treatment and study day. An exploratory analysis for a relationship between plasma SVA concentrations after multiple dosing and LDL-C concentrations (actual and their changes from baseline) was done by correlation methods.

On the basis of previous (internal) study data, a sample size of at least 78 subjects with 3 periods would permit to demonstrate $90 \%$ CI to be between 80 and $125 \%$, i.e., criteria accepted for bioequivalence, with a power of at least $90 \%$ for the $\mathrm{B} / \mathrm{C}$ comparison and to evidence at least $23 \%$ difference with $90 \%$ power for the $\mathrm{B} / \mathrm{A}$ and $\mathrm{C} / \mathrm{A}$ comparisons. A total of 84 subjects (14 per sequence) were planned to be randomized.

\section{Results}

Of the 85 subjects who entered the study, 81 qualified for the pharmacokinetic (PK) analysis and 79 completed the trial as planned. Three subjects withdrew prematurely from the study due to adverse events (during period 1), 2 withdrew their consent (at the end of period 1 and 2, respectively) and one subject was withdrawn due to pregnancy (after period 2).

Treatments will be denoted as "A", "B", and "C":

Treatment A: simvastatin $40 \mathrm{mg}$ taken in the evening on day 1 to day 7 .

Treatment B: simvastatin $40 \mathrm{mg}$ and fenofibrate $145 \mathrm{mg}$ taken together in the evening on day 1 to day 7 .

Treatment $C$ : simvastatin $40 \mathrm{mg}$ taken in the evening and fenofibrate $145 \mathrm{mg}$ taken in the morning on day 1 to day 7 ( 12 hours before the simvastatin dosing).

\section{Pharmacokinetics of Simvastatin}

Mean peak plasma concentrations of simvastatin on day 1 were somewhat higher after treatments $\mathrm{B}$ and $\mathrm{C}$ than after treatment A (Figure 1). Otherwise the mean plasma concentration profiles for simvastatin were similar after all three treatments both on day 1 and day 7 .

Table 1 shows that the mean PK parameters for simvastatin were comparable for all three treatment regimens both after single (day 1) and multiple dosing (day 7).

\section{Pharmacokinetics of Simvastatin Acid (SVA)}

Peak plasma concentrations for SVA were reached earlier after treatments B and C than after treatment A, both after single and multiple dosing (Figure 2).

The median $\mathrm{T}_{\max }$ for $\mathrm{SVA}$ with treatments $\mathrm{B}$ and $\mathrm{C}$ was 1-2 hours earlier compared to the median $\mathrm{T}_{\max }$ with treatment $\mathrm{A}$. The mean $\mathrm{C}_{\max }$ for SVA was the highest when fenofibrate and simvastatin were coadministered at the same time (treatment $\mathrm{B}$ ) both after single and multiple dosing (Table 2).

\section{Statistical Analysis of $A U C_{0-24 h}$ and $C_{\max }$ for Simvastatin and SVA}

Comparisons of the $\mathrm{AUC}_{0-24 \mathrm{~h}}$ and $\mathrm{C}_{\max }$ of simvastatin showed no statistically significant differences between the three treatments. The treatment ratios and their $90 \% \mathrm{CI}$ were all within the $80-125 \%$ range accepted for bioequivalence (Table 3).

Compared to simvastatin monotherapy, a mean reduction in the SVA $\mathrm{AUC}_{0-24 \mathrm{~h}}$ was observed on day 7 when simvastatin treatment was combined with fenofibrate simultaneously and 12 hours apart. The geometric mean ratios and $90 \% \mathrm{CI}$ for SVA $\mathrm{AUC}_{0-24 \mathrm{~h}}$ were $79.4 \%$ (72.9-86.4) for $\mathrm{B} / \mathrm{A}$ and $71.2 \%(65.4-77.5)$ for $\mathrm{C} / \mathrm{A}$ (Table 3). A reduction in SVA exposure was not observed on day 1 although the SVA $\mathrm{AUC}_{0-24 \mathrm{~h}}$ for treatment $\mathrm{C}$ was slightly lower than for the other treatments.

Statistical comparison of the SVA $\mathrm{AUC}_{0-24 \mathrm{~h}}$ on day 7 for both modes of coadministration of fenofibrate and simvastatin $(\mathrm{B} / \mathrm{C})$ resulted in a geometric mean ratio and $90 \%$ CI of $111.4 \%(102.3-121.4)$.

\section{SLCOIBI Polymorphisms}

All subjects were genotyped for SLCO1B1 single nucleotide polymorphisms $521 \mathrm{~T}>\mathrm{C}$ and $388 \mathrm{~A}>\mathrm{G}$. These polymorphisms affect the PK of SVA but not of simvastatin. ${ }^{5,6}$ Information on genotyping was not used as selection criterion but in order to possibly explain outlying pharmacokinetic values. One subject showed outlying plasma concentrations for SVA on days 1 and 7 during treatment $\mathrm{A}$ (simvastatin only): $\mathrm{AUC}_{0-24 \mathrm{~h}}$ values were 130 and $124 \mathrm{ng} \mathrm{h} / \mathrm{mL}$, respectively, i.e. about five to six times the respective mean values. This subject was found homozygous for the $521 \mathrm{~T}>\mathrm{C}$, a common variant of the SLCO1B1 gene associated with increased SVA plasma concentrations and an increased risk of myopathy. ${ }^{7}$ This subject experienced no signs of myopathy or other clinically significant events during and after 

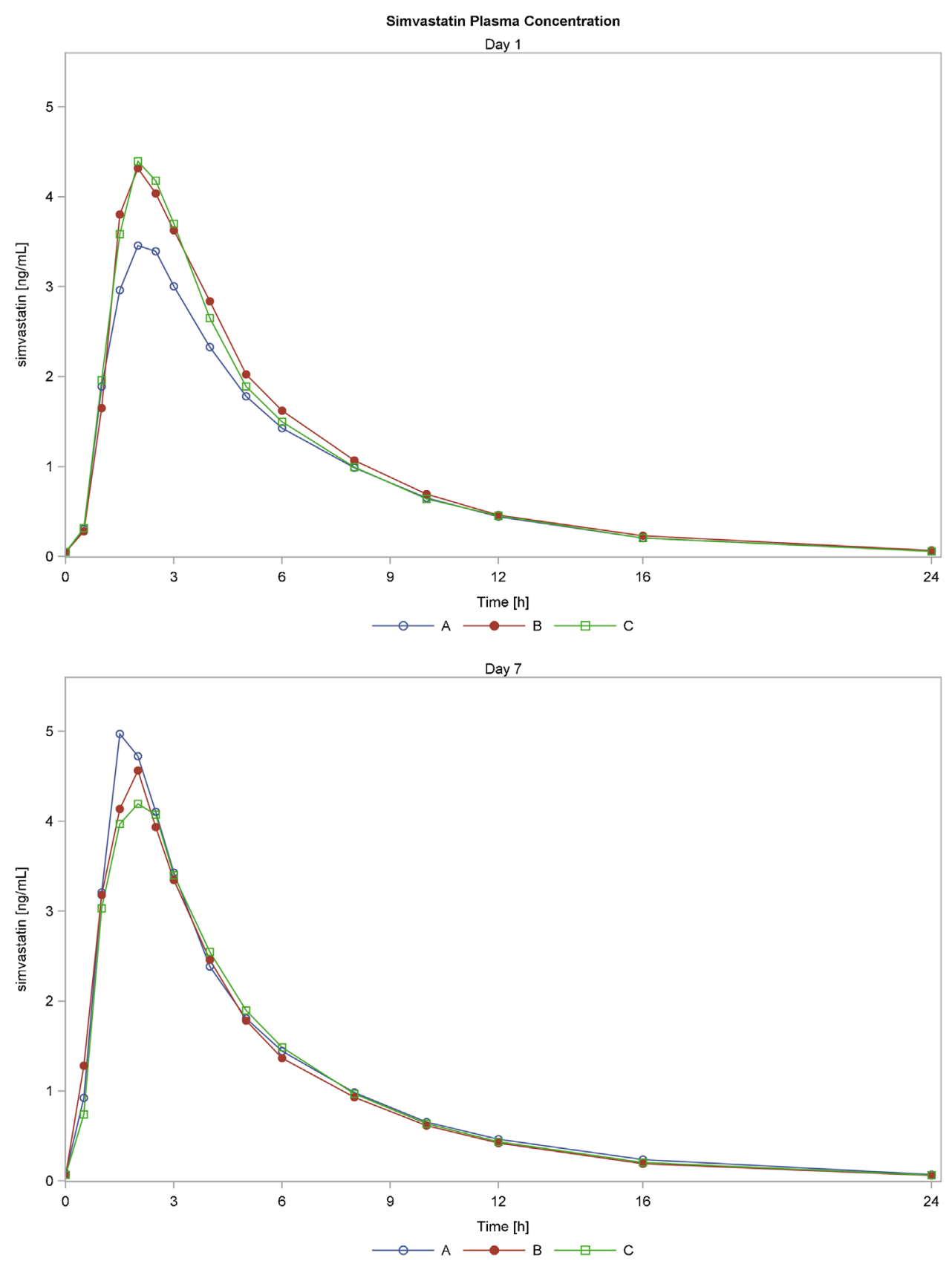

Figure I. Mean plasma concentration profiles of simvastatin after a single dose (day I) or multiple doses (day 7 ) for treatment $A$ (simvastatin $40 \mathrm{mg}$ in the evening), treatment B (simvastatin $40 \mathrm{mg}$ and fenofibrate $145 \mathrm{mg}$ taken together in the evening), or treatment $C$ (simvastatin $40 \mathrm{mg}$ taken in the evening and fenofibrate $145 \mathrm{mg}$ taken in the morning).

treatment of simvastatin only. Further information on safety and exposure to SVA for the combination regimens in view of this homozygous variant genotype could not be obtained, as this was the only carrier enrolled in the study and the subject withdrew consent in Period 2, before completing any combination treatment.

\section{Pharmacokinetics of Fenofibric Acid}

Based on the study results from Bergman et $\mathrm{al}^{2}$, which found no relevant changes in fenofibric acid pharmacoki- netics, no full profiles for fenofibric acid were determined, but only trough concentrations to confirm steady state were reached (Table 4).

After both treatments B and C, steady state plasma concentrations of fenofibric acid appeared to have been reached at the time of multiple dose PK profiling (day 78) for simvastatin and SVA. Fenofibric acid concentrations were slightly higher with treatment B (both drugs taken together) than with treatment $\mathrm{C}$ (drugs taken 12 hours apart). 
Table I. Pharmacokinetic Parameters of Simvastatin

\begin{tabular}{|c|c|c|c|c|c|c|}
\hline & \multicolumn{2}{|c|}{ Treatment $\mathrm{A}(\mathrm{N}=8 \mathrm{I})$ mean $(\mathrm{SD})$} & \multicolumn{2}{|c|}{ Treatment $B(N=79)$ mean $(S D)$} & \multicolumn{2}{|c|}{ Treatment $C(N=8 I)$ mean $(S D)$} \\
\hline & Day I & Day 7 & Day I & Day 7 & Day I & Day 7 \\
\hline $\mathrm{AUC}_{0-24 \mathrm{~h}}(\mathrm{ng} \mathrm{h} / \mathrm{mL})$ & $28.4(12.9)$ & $30.0(12.0)$ & $30.9(12.6)$ & $29.1(10.9)$ & $29.7(11.8)$ & $29.0(11.6)$ \\
\hline $\mathrm{C}_{\max }(\mathrm{ng} / \mathrm{mL})$ & $9.2(5.8)$ & $9.9(7.0)$ & $9.9(6.2)$ & $10.0(5.5)$ & $9.7(5.4)$ & $10.3(7.2)$ \\
\hline AUC (ng h/mL) & $28.7(13.0)$ & - & $30.5(11.5)^{\mathrm{a}}$ & - & $30.3(11.9)^{b}$ & - \\
\hline$t_{\max }(h)^{c}$ & $1.5(0.5-8.0)$ & $1.5(0.5-6.0)$ & $1.5(0.5-16.0)$ & I.5 (0.5-5.0) & $1.5(0.5-6.0)$ & $1.5(0.5-6.0)$ \\
\hline $\mathrm{t}_{\mathrm{I} / 2}(\mathrm{~h})$ & $3.8(0.8)$ & - & $3.7(0.7)^{\mathrm{a}}$ & - & $3.9(0.9)^{\mathrm{b}}$ & - \\
\hline$\lambda_{z}(\mathrm{I} / \mathrm{h})$ & $0.188(0.037)$ & - & $0.194(0.038)^{\mathrm{a}}$ & - & $0.189(0.040)^{b}$ & - \\
\hline CL/F (L/h) & $1652(683)$ & - & $|49|(545)^{\mathrm{a}}$ & - & $1537(628)^{b}$ & - \\
\hline $\mathrm{V}_{\mathrm{z}} / \mathrm{F}(\mathrm{L})$ & 8901 (3480) & - & $7815(2765)^{\mathrm{a}}$ & - & $8362(3867)^{b}$ & - \\
\hline$C_{\min }(\mathrm{ng} / \mathrm{mL})$ & - & $0.05(0.07)$ & - & $0.02(0.05)$ & - & $0.03(0.06)$ \\
\hline $\mathrm{C}_{\text {avg }}(\mathrm{ng} / \mathrm{mL})$ & - & I.3 (0.5) & - & $1.2(0.5)$ & - & $1.2(0.5)$ \\
\hline PTF $(\%)^{d}$ & - & $794(374)$ & - & $834(352)$ & - & $821(315)$ \\
\hline
\end{tabular}

${ }^{\mathrm{a}} \mathrm{N}=77$.

${ }^{\mathrm{b}} \mathrm{N}=80$.

'Median and range.

'PTF: peak trough fluctuation.

Treatment A: simvastatin $40 \mathrm{mg}$ in the evening. Treatment B: simvastatin $40 \mathrm{mg}$ and fenofibrate $145 \mathrm{mg}$ taken together in the evening. Treatment C: simvastatin $40 \mathrm{mg}$ taken in the evening and fenofibrate $145 \mathrm{mg}$ taken in the morning.

\section{Pharmacodynamics}

Baseline (day 1) lipid marker concentrations were similar in all three treatment groups: ranges of mean concentrations across the three treatment groups on day 1 were $3.96-4.09 \mathrm{mmol} / \mathrm{L}$ (total cholesterol), $2.42-2.50 \mathrm{mmol} / \mathrm{L}$ (LDL-C), $\quad 1.24-1.31 \mathrm{mmol} / \mathrm{L}$ (HDL-C), and $0.96-$ $1.00 \mathrm{mmol} / \mathrm{L}$ (triglyceride). On day 8 , an expected decrease from day 1 was observed for mean total cholesterol, LDL-C, and triglycerides, which was similar for all three treatment groups. The ranges of mean concentrations on day 8 across the three treatment groups were $\quad 2.80-2.97 \mathrm{mmol} / \mathrm{L}$ (total cholesterol), $1.36-$ $1.51 \mathrm{mmol} / \mathrm{L}$ (LDL-C), and $0.62-0.79 \mathrm{mmol} / \mathrm{L}$ (triglyceride). The mean HDL-C concentrations on day 8 (range of mean concentrations being $1.25-1.29 \mathrm{mmol} / \mathrm{L}$ ) were similar to those on day 1 in all three treatment groups.

Exploratory analyses of a possible relation between LDL-C concentrations on day 8 (actual and changes from baseline) and SVA $\mathrm{AUC}_{0-24 \mathrm{~h}}$ suggest no correlation for any of the three treatment regimens.

\section{Safety and Tolerability}

The three treatment regimens in the study were well tolerated. Most adverse events were reported after treatment with simvastatin and fenofibrate given 12 hours apart: the number of subjects with at least one treatment emergent adverse event (TEAE) was 19 for simvastatin $40 \mathrm{mg}$ alone, 24 for simvastatin $40 \mathrm{mg}$ combined with fenofibrate $145 \mathrm{mg}$ at the same time, and 35 for simvastatin $40 \mathrm{mg}$ combined with fenofibrate $145 \mathrm{mg}$ 12 hours apart. The most frequently reported TEAEs were headache and myalgia. Three subjects withdrew from the study due to adverse events of increased blood pressure and tachycardia; these events were not considered drugrelated and resolved without any treatment.

There were two single reports of clinically significant abnormal laboratory values during the study (increased creatine kinase level at end of treatment $\mathrm{C}$ and increased myoglobin level on day 1 before start of treatment $\mathrm{C}$ ) which resolved without sequelae.

\section{Discussion}

In the study conducted by Bergman et al, a pharmacokinetic interaction leading to a $36 \%(90 \%$ CI: $30-42)$ reduction in $\mathrm{AUC}_{0-24 \mathrm{~h}}$ of SVA was observed when simvastatin $80 \mathrm{mg}$ was simultaneously coadministered with fenofibrate $160 \mathrm{mg}^{2}$ In the present study, the mean reduction for the $\mathrm{AUC}_{0-24 \mathrm{~h}}$ of SVA after multiple dosing of simvastatin and fenofibrate was smaller: $21 \%$ ( $90 \% \mathrm{CI}$ : 14-27) when simvastatin $40 \mathrm{mg}$ and fenofibrate $145 \mathrm{mg}$ were combined simultaneously and 29\% (90\% CI: $22-35$ ) when they were administered in staggered intervals. Multiple doses of fenofibrate $145 \mathrm{mg}$ had no impact on the $\mathrm{AUC}_{0-24 \mathrm{~h}}$ and $\mathrm{C}_{\text {max }}$ of the parent compound simvastatin, which is consistent with findings in the Bergman study. In view of the large variability in the SVA pharmacokinetic data (CV for SVA $\mathrm{AUC}_{0-24 \mathrm{~h}}$ being $90-100 \%$ ) and the limited number of subjects enrolled in the Bergman study, a larger sample size was employed in this study. The variability in the SVA pharmacokinetic data from the present study was somewhat lower with a CV for SVA $\mathrm{AUC}_{0-24 \mathrm{~h}}$ of about $60-80 \%$. Although the difference in the degree of interaction between the two studies might be attributed to a difference in strength of the simvastatin dose, we consider that the present study was appropriately 

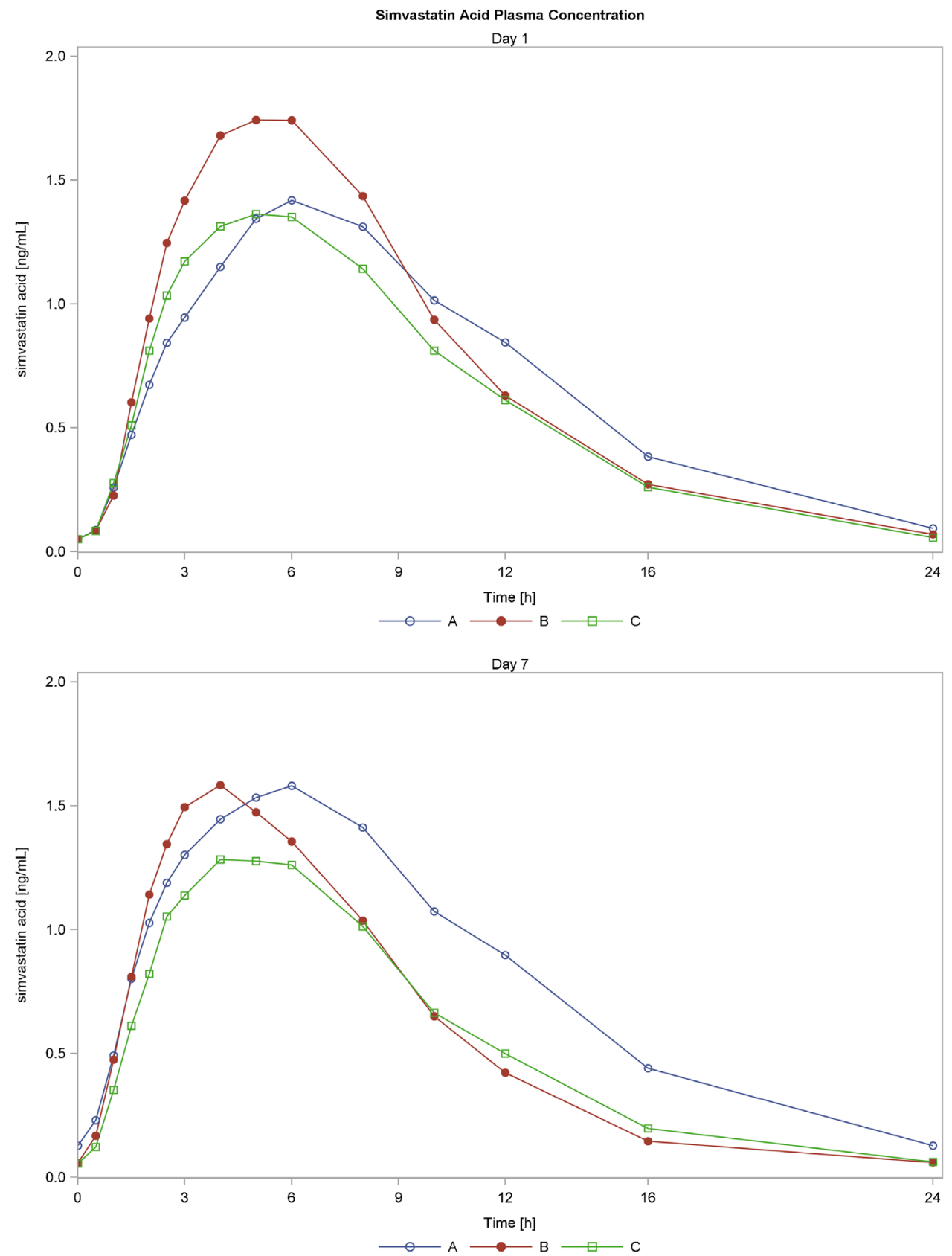

Figure 2. Mean plasma concentration profiles of simvastatin acid after a single dose (day I) or multiple doses (day 7 ) for treatment $A$ (simvastatin $40 \mathrm{mg}$ in the evening), treatment B (simvastatin $40 \mathrm{mg}$ and fenofibrate $145 \mathrm{mg}$ taken together in the evening), or treatment $C$ (simvastatin $40 \mathrm{mg}$ taken in the evening and fenofibrate $145 \mathrm{mg}$ taken in the morning).

designed to conclusively assess the magnitude of the pharmacokinetic interaction between simvastatin $(40 \mathrm{mg})$ and fenofibrate $(145 \mathrm{mg})$. The difference in strength of the fenofibrate dose is unlikely to affect the degree of interaction as the $160 \mathrm{mg}$ formulation used in the Bergman's study and the $145 \mathrm{mg}$ nano-particle formulation used in this study have comparable bioavailability (internal data).

The geometric mean ratio of the SVA $\mathrm{AUC}_{0-24 \mathrm{~h}}$ for the two combined dosing regimens and its $90 \%$ CI were $111 \%(102-121)$ which is within the prespecified bounds of 80 and $125 \%$. Thus, the SVA exposures after the two combined treatment regimens were essentially similar, meeting criteria accepted for demonstration of bioequivalence. This result indicates that the drug-drug interaction is not a unique feature to the simultaneous combination of simvastatin and fenofibrate, but also occurs under the staggered combination in an essentially similar order of magnitude. In the 5-year ACCORD (Action to Control Cardiovascular Risk in Diabetes) Lipid study, a clinical benefit of fenofibrate/simvastatin combination therapy as compared to simvastatin monotherapy has been shown: 
Table 2. Pharmacokinetic Parameters of Simvastatin Acid

\begin{tabular}{|c|c|c|c|c|c|c|}
\hline & \multicolumn{2}{|c|}{ Treatment $A(N=8 I)$ mean $(S D)$} & \multicolumn{2}{|c|}{ Treatment $B(N=79)$ mean $(S D)$} & \multicolumn{2}{|c|}{ Treatment $C(N=8 I)$ mean $(S D)$} \\
\hline & Day I & Day 7 & Day I & Day 7 & Day I & Day 7 \\
\hline$A \cup C_{0-24 h}(\mathrm{ng} \mathrm{h} / \mathrm{mL})$ & $21.4(16.9)$ & $23.7(17.2)$ & $22.0(12.7)$ & $18.0(11.0)$ & $18.8(11.8)$ & $16.3(10.8)$ \\
\hline $\mathrm{C}_{\max }(\mathrm{ng} / \mathrm{mL})$ & $2.2(1.6)$ & $2.4(1.6)$ & $2.8(1.6)$ & $2.7(1.2)$ & $2.2(1.3)$ & $2.2(1.3)$ \\
\hline $\mathrm{AUC}(\mathrm{ng} \mathrm{h} / \mathrm{mL})$ & $22.4(\mid 8.1)^{\mathrm{a}}$ & - & $22.5(13.4)^{\mathrm{b}}$ & - & $18.8(12.1)^{\mathrm{a}}$ & - \\
\hline$t_{\max }(h)^{c}$ & $6.0(0.5-12.0)$ & $5.0(0.5-10.0)$ & $4.0(0.5-10.0)$ & $3.0(0.5-10.0)$ & $4.0(0.5-12.0)$ & $4.0(0.5-8.0)$ \\
\hline$t_{1 / 2}(h)$ & $4.4(1.4)^{\mathrm{d}}$ & - & $3.4(0.9)^{\mathrm{d}}$ & - & $3.8(1.1)^{\mathrm{e}}$ & - \\
\hline$\lambda_{z}(\mathrm{I} / \mathrm{h})$ & $0.173(0.048)^{d}$ & - & $0.216(0.05 \mathrm{I})^{\mathrm{d}}$ & - & $0.198(0.054)^{\mathrm{e}}$ & - \\
\hline $\mathrm{C}_{\min }(\mathrm{ng} / \mathrm{mL})$ & - & $0.11(0.13)$ & - & $0.02(0.05)$ & - & $0.02(0.08)$ \\
\hline $\mathrm{C}_{\text {avg }}(\mathrm{ng} / \mathrm{mL})$ & - & $1.0(0.7)$ & - & $0.8(0.5)$ & - & $0.7(0.5)$ \\
\hline PTF $(\%)^{f}$ & - & $254(83.3)$ & - & 400 (135) & - & $346(116)$ \\
\hline
\end{tabular}

${ }^{\mathrm{a}} \mathrm{N}=69$.

${ }^{\mathrm{b}} \mathrm{N}=75$.

${ }^{\mathrm{C}}$ Median and range.

${ }^{\mathrm{d}} \mathrm{N}=76$.

${ }^{\mathrm{e}} \mathrm{N}=78$.

fPTF: peak trough fluctuation.

Treatment A: simvastatin $40 \mathrm{mg}$ in the evening. Treatment B: simvastatin $40 \mathrm{mg}$ and fenofibrate $145 \mathrm{mg}$ taken together in the evening. Treatment C: simvastatin $40 \mathrm{mg}$ taken in the evening and fenofibrate $145 \mathrm{mg}$ taken in the morning.

prespecified subgroup analysis of the ACCORD Lipid study showed a significant reduction in cardiovascular death, nonfatal myocardial infarction, and nonfatal stroke when compared with simvastatin monotherapy in dyslipidemic patients at baseline. ${ }^{1}$ In the ACCORD Lipid study, a treatment regimen of fenofibrate administration in the morning and simvastatin in the evening was applied. Thus, despite the observed pharmacokinetic interaction for the combination of simvastatin and fenofibrate in the present study, clinical benefits have been found for the staggered combination compared with simvastatin monotherapy in the ACCORD study. Based on these clinical findings, it is considered that the pharmacokinetic interaction observed between the two drugs is not clinically meaningful.

Although the present study used short (7-day) treatment regimens and data were obtained in healthy subjects, it should be noted that the measured lipid markers behaved similarly after both simvastatin only and simvastatin coadministered with fenofibrate - simultaneously or in staggered intervals. Mean plasma concentrations of total and LDL cholesterol and triglycerides were decreased after 7-day treatment, which were similar for all three treatments, whereas the mean HDL-C

Table 3. Summary of the Statistical Analyses for SVA and Simvastatin Day I and Day 7

\begin{tabular}{|c|c|c|c|c|c|}
\hline \multirow[b]{2}{*}{ Comparison } & \multirow[b]{2}{*}{ Parameter } & \multicolumn{2}{|c|}{ Simvastatin acid } & \multicolumn{2}{|c|}{ Simvastatin } \\
\hline & & Geometric mean Ratio (\%) & $90 \% \mathrm{Cl}$ & Geometric mean Ratio (\%) & $90 \% \mathrm{Cl}$ \\
\hline \multicolumn{6}{|l|}{ Day I $(\mathrm{N}=8 \mathrm{I})$} \\
\hline Treatment B/C & $\mathrm{AUC}_{0-24 \mathrm{~h}}$ & 123.2 & $114.1-132.9$ & 105.5 & $99.5-111.8$ \\
\hline Treatment B/A & $A \cup C_{0-24 h}$ & 109.4 & $101.3-118.0$ & 111.6 & $105.3-118.3$ \\
\hline Treatment C/A & $\mathrm{AUC}_{0-24 \mathrm{~h}}$ & 88.8 & $82.4-95.8$ & 105.8 & $99.9-112.1$ \\
\hline Treatment $\mathrm{B} / \mathrm{C}$ & $\mathrm{C}_{\max }$ & 130.6 & $|2| .|-| 40.8$ & 100.1 & $90.0-111.5$ \\
\hline Treatment B/A & $\mathrm{C}_{\max }$ & 133.9 & |24.2-144.4 & 107.9 & $97.0-120.1$ \\
\hline Treatment $\mathrm{C} / \mathrm{A}$ & $\mathrm{C}_{\max }$ & 102.6 & $95.2-110.5$ & 107.8 & $96.9-119.9$ \\
\hline \multicolumn{6}{|l|}{ Day $7(\mathrm{~N}=80)$} \\
\hline Treatment B/C & $A \cup C_{0-24 h}$ & 111.4 & $102.3-121.4$ & 100.9 & $96.2-105.9$ \\
\hline Treatment B/A & $\mathrm{AUC}_{0-24 \mathrm{~h}}$ & 79.4 & $72.9-86.4$ & 98.3 & $93.7-103.2$ \\
\hline Treatment C/A & $A \cup C_{0-24 h}$ & 71.2 & $65.4-77.5$ & 97.4 & $92.9-102.2$ \\
\hline Treatment $\mathrm{B} / \mathrm{C}$ & $\mathrm{C}_{\max }$ & 128.2 & $118.8-138.4$ & 99.9 & $89.6-111.3$ \\
\hline Treatment B/A & $\mathrm{C}_{\max }$ & 120.3 & $111.4-129.9$ & 102.2 & $91.7-113.9$ \\
\hline Treatment C/A & $\mathrm{C}_{\max }$ & 93.8 & $86.9-101.2$ & 102.4 & $91.9-114.0$ \\
\hline
\end{tabular}

Treatment A: simvastatin $40 \mathrm{mg}$ in the evening. Treatment B: simvastatin $40 \mathrm{mg}$ and fenofibrate $145 \mathrm{mg}$ taken together in the evening. Treatment C: simvastatin $40 \mathrm{mg}$ taken in the evening and fenofibrate $145 \mathrm{mg}$ taken in the morning. 
Table 4. Fenofibric Acid Trough Concentrations, $\mathrm{ng} / \mathrm{mL}$

\begin{tabular}{lccc}
\hline Treatment & $\begin{array}{c}\text { Day 6 } \\
\text { mean (SD) }\end{array}$ & $\begin{array}{c}\text { Day 7 } \\
\text { mean (SD) }\end{array}$ & $\begin{array}{c}\text { Day 8 } \\
\text { mean (SD) }\end{array}$ \\
\hline B & $4381(2016)$ & $4526(2188)$ & $4631(2243)$ \\
C & $3966(1968)$ & $3995(1951)$ & $4017(2005)$ \\
\hline
\end{tabular}

Treatment B: simvastatin $40 \mathrm{mg}$ and fenofibrate $145 \mathrm{mg}$ taken together in the evening. Treatment $C$ : simvastatin $40 \mathrm{mg}$ taken in the evening and fenofibrate $145 \mathrm{mg}$ taken in the morning.

concentrations were not different on days 1 and 8 . Although no confirmatory inferences can be drawn from these results regarding the long-term applicability of this finding to patients, the data suggest that the observed interaction causing a reduction in $\mathrm{SVA} \mathrm{AUC}_{0-24 \mathrm{~h}}$ does not lead to a reduction in "treatment" effect on lipid markers at least after 7-day treatment. Exploratory analyses suggested no relation between LDL-C concentrations on day 8 (actual and changes from baseline) and SVA $\mathrm{AUC}_{0-24 \mathrm{~h}}$ for any of the three treatment regimens. It is possible that other active metabolites, possibly contributing to the activity of HMG-CoA reductase inhibition, compensate for the reduction in SVA exposure. This hypothesis, however, was not examined in the present study.

This study was not designed to investigate the cause of the interaction between simvastatin and fenofibrate. Previous studies investigating the combination of fenofibrate with other statins including atorvastatin, rosuvastatin, and pravastatin reported that the pharmacokinetics of these statins were not affected by fenofibrate coadministration. ${ }^{8,9,10}$ The mechanism by which fenofibrate coadministration leads to reduced SVA plasma concentrations is as yet unknown. Several mechanisms can be postulated, such as interference with biotransformation, transport, or plasma protein binding of simvastatin and/or SVA. ${ }^{11}$ Fenofibrate is metabolized rapidly into fenofibric acid and since no parent compound can be detected in plasma, it is unlikely that fenofibrate caused the observed effects.

Decreased $\mathrm{T}_{\max }$ and lowered AUC of SVA are important aspects of the observed drug-drug interaction, which could imply that SVA is more rapidly eliminated when fenofibrate is coadministered. Metabolic enzyme induction (i.e., CYP enzymes) by fenofibric acid may account for such a phenomenon. However, as simvastatin and SVA can be transformed into each other and as the same isozymes (i.e., CYP2C8 and CYP3A4) are involved in the metabolism of the two compounds, this mechanism is considered unlikely since only SVA but not simvastatin exposure was affected. The involvement of esterases such as carboxylesterase in the biotransformation of simvastatin into SVA has been suggested. ${ }^{11}$ Inhibition of this process will result in less formation of SVA and could thus at least partly explain a decrease in SVA AUC without affecting simvastatin exposures. ${ }^{12}$ However, of important note is that an earlier $\mathrm{T}_{\max }$ for SVA when fenofibrate is coadministered, an observation also made by Bergman et al in their study, reflects a faster appearance of the metabolite. Since exposures of the parent simvastatin were unchanged, it may be that the rate, but not the extent of SVA formation was slightly increased. In contrast to these clinical observations, interference with carboxylesterase will unlikely increase the rate of SVA formation, but rather is expected to delay $\mathrm{T}_{\max }$ for the SVA.

Alternatively, a modification in transporter function might explain a reduction in SVA exposure. Indeed, organic anion transporting peptide 1B1 (OATP1B1) has been recognized to play an essential role in the elimination of many statins. ${ }^{5}$ A study on genetic polymorphism of SLCO1B1, the gene coding for OATP1B1, clearly showed a selective transport of SVA but not simvastatin via the OATP1B $1 .{ }^{6}$ In in vitro studies, inhibition of OATP1B1 transporters by fenofibric acid and fenofibrate has been reported at concentrations much higher than clinically anticipated plasma concentrations. ${ }^{13}$ Contrary to our finding, however, inhibition of OATP1B1 transport would lead to increased SVA plasma concentrations. Induction of OATP1B1 transporters might theoretically explain the reduction in SVA exposure observed in the study. In vitro, it is not known whether fenofibric acid can induce OATP transporters in the hepatocyte. However, an in vivo study with repaglinide, a substrate for OATP1B1, showed that multiple administration of fenofibrate does not affect the pharmacokinetic profile of repaglinide, thus suggesting that fenofibrate does not induce OATP1B1 transport. ${ }^{14}$ This is further supported by the fact that multipledosing of fenofibrate does not affect pharmacokinetics of atorvastatin and rosuvastatin, for which involvement of OATP1B1 in drug disposition has been demonstrated. ${ }^{8,10}$ Interaction involving P-glycoprotein transport is considered unlikely as fenofibrate, fenofibric acid and SVA are not known to be substrates of this transporter. ${ }^{11,13,15}$ Drug-drug interaction based on plasma protein binding can also be excluded, since therapeutically relevant concentrations of fenofibric acid did not affect the plasma protein binding of SVA (data not shown).

There exist potential underlying mechanisms that might explain the phenomena mentioned above and could contribute to the modification of simvastatin (acid) metabolism when fenofibrate is coadministered. However, they mostly rely on in vitro experiments with contradictory results and do not reveal any putative cause of the observed interaction. Understanding of the observed interaction, therefore, warrants further investigations, although the fact that the degree of interaction is limited may hamper clarifications of the potential 
mechanism for the AUC reduction in SVA when simvastatin and fenofibrate are coadministered.

In general caution should be used when prescribing statins with fibrates, as these drugs can cause myopathy when given alone and the risk is increased when given together. In the present study, no relevant safety findings were observed. It is noteworthy that the subject in our study with dramatically increased SVA values experienced no signs of myopathy or other clinically significant events.

In conclusion, the present study shows that the interaction between simvastatin and fenofibrate occurs in essentially the same order of magnitude irrespective of the combination regimen. The degree of the interaction is considered minimal to cause any clinically meaningful impact. These findings do support the combined use of simvastatin and fenofibrate either given simultaneously or at staggered intervals. While dosing at staggered intervals may allow for flexibility in the treatment regimen, simultaneous dosing could have an advantage in terms of patient compliance for drug intake, for which a fixeddose combination formulation is an attractive option.

\section{Acknowledgements}

We thank Nuvisan GmbH, Germany and MLM medical labs, Germany for their efforts in the performance of the study and analysis of the study data.

\section{Declaration of Conflicting Interests}

Jean-Claude Ansquer is currently at ClinSciences, France; he was employee of Abbott at the time of the study. Dirk Lehnick and Gabi Piskol are employees of Nuvisan, the CRO that performed the study. All other authors are employees of Abbott.

\section{Funding}

This study was funded by Abbott, Established Pharmaceuticals.

\section{References}

1. Ginsberg HN, Elam MB, Lovato LC, et al. Effects of combination lipid therapy in type 2 diabetes mellitus. $N$ Eng $J$ Med. 2010;362:1563-1574.
2. Bergman AJ, Murphy G, Burke J, et al. Simvastatin does not have a clinically significant pharmacokinetic interaction with fenofibrate in humans. J Clin Pharmacol. 2004;44:1054-1062.

3. EMA Guideline on bioanalytical method validation. London, 21 July 2011 EMA/CHMP/EWP/192217/2009.

4. EMA Guideline on the investigation of bioequivalence. London, 20 January 2010 CPMP/EWP/QWP/1401/98 Rev. 1/ Corr **.

5. Niemi M, Pasanen MK, Neuvonen PJ. Organic anion transporting polypeptide 1B1: a genetically polymorphic transporter of major importance for hepatic drug uptake. Pharmacol Rev. 2011;63:157181.

6. Pasanen MK, Neuvonen M, Neuvonen PJ, Niemi M. SLCO1B1 polymorphism markedly affects the pharmacokinetics of simvastatin acid. Pharmacogenet Genomics. 2006;16:873-879.

7. Wilke RA, Ramsey LB, Johnson SG, et al. The clinical pharmacogenomics implementation consortium: CPIC guideline for SLCO1B1 and simvastatin-induced myopathy. Clin Pharmacol Ther. 2012;92:112-117.

8. Whitfield LR, Porcari AR, Alvey C, Abel R, Bullen W, Hartman D. Effect of gemfibrozil and fenofibrate on the pharmacokinetics of atorvastatin. J Clin Pharmacol. 2011;51:378-388.

9. Pan WJ, Gustavson L, Achari R, et al. Lack of a clinically significant pharmacokinetic interaction between fenofibrate and pravastatin in healthy volunteers. J Clin Pharmacol. 2000;40:316-323.

10. Martin PD, Dane AL, Schneck DW, Warwick MJ. An open-label, randomized, three-way crossover trial of the effects of coadministration of rosuvastatin and fenofibrate on the pharmacokinetic properties of rosuvastatin and fenofibric acid in healthy male volunteers. Clin Ther. 2003;25:459-471.

11. Elsby R, Hilgendorf C, Kenner K. Understanding the critical pathways of statins to assess drug-drug interaction risk during drug development: it's not just about OATP1B1. Clin Pharmacol Ther. 2012;92:584-598.

12. Fukami T, Takahashi S, Nakagawa N, Maruichi T, Nakajima M, Yokoi T. In vitro evaluation of inhibitory effects of antidiabetic and antihyperlipidemic drugs on human carboxylesterase activities. Drug Metab Dispos. 2010;38:2173-2178.

13. Yamazaki M, Li B, Louie SW, et al. Effects of fibrates on human organic anion-transporting polypeptide 1B1-, multidrug resistance protein 2- and P-glycoprotein-mediated transport. Xenobiotica. 2005;35:737-753.

14. Kajosaari LI, Backman JT, Neuvonen M, Laitila J, Neuvonen PJ. Lack of effect of bezafibrate and fenofibrate on the pharmacokinetics and pharmacodynamics of repaglinide. Br J Clin Pharmacol. 2004;58:390-396.

15. Li J, Volpe DA, Wang Y, et al. Use of transporter knockdown Caco2 cells to investigate the in vitro efflux of statin drugs. Drug Metab Dispos. 2011;39:1196-1202. 